\title{
Study and Application of Permitted Yield Point Control Boundary of Drilling Fluid
}

\author{
Yao Ru-Gang ${ }^{* 1,2}$, Jiang Guan-Cheng ${ }^{1,2}$, Li Wei ${ }^{1,2}$, Wang Yu-Zhe ${ }^{1,2}$, Zhang Hong-Xia ${ }^{3}$ and \\ Fan Jin ${ }^{1,2}$ \\ ${ }^{I}$ State Key Laboratory of Petroleum Resources and Prospecting, China University of Petroleum, Beijing, China; ${ }^{2} M O E$ \\ Key Laboratory of Petroleum Engineering, China University of Petroleum, Beijing 102249, China; ${ }^{3}$ Drilling Fluid \\ Branch, PetroChina Great Wall Drilling Company, Panjin 124010, China
}

\begin{abstract}
To consider the needs for drilling and the principles of carry and suspend formation cuttings, the permitted yield point control boundary model of drilling fluid was derived using solid-liquid dynamics under certain given assumptions. Corresponding calculation software was developed in $\mathrm{c} \#$. The results show that: Any one of the drilling fluid density, pump discharge, plastic viscosity and drilling fluid pump cylinder bore increases would result in the permitted yield point control boundary which turned out to be narrow. Drilling fluid pump discharge is the main cause of the decrease in the upper range of the permitted yield point control boundary. While drilling fluid density is the main cause of the decrease in the lower range. Application had shown the practicality and accuracy of this model in Tarim oil field KS8 well.
\end{abstract}

Keywords: Drilling fluid, model, permitted yield point control boundary, software, solid-liquid dynamics.

\section{INTRODUCTION}

Drilling fluid technology is an important part of drilling. Regulation and control of drilling fluid rheological properties are known to be among the focuses of the drilling fluid technology. Experimental charts are proposed to regulate drilling fluid properties for field personnel; however, there is hardly any theory chart. Problems associated with inefficient cuttings transport are; reduction in penetration rate, wear of bit, pipe stuck, high torque and drag and other borehole problems. To carry formation cuttings sufficiently, drilling fluid rheological parameters such as plastic viscosity and yield point, are required within reasonable limits [1]. High plastic viscosity and yield point may cause excessive circulating pressure loss. Precise estimation of circulating pressure loss is essential in drilling and well completion operations to control formation pressures and optimize drilling and completion fluids hydraulic programs [2]. Increase of Equivalent Circulating Density (ECD) may result in the fractured of formation, or it may result in that the needed pump pressure for circulation out of its rated pressure. What is more, a series of other emergencies is in the consequent. A lot of theoretical, field data, and experimental studies on pressure loss have been carried out [3-10]. Since the rated pressure of pump is certain, and allowed pressure loss in circulation should be smaller than rated pressure of pump, it is possible to evaluate the upper boundary of the drilling fluid yield point with high precision. In addition, the maximum critical yield point is

*Address correspondence to this author at the Department of Petroleum Engineering, China University of Petroleum, Beijing 102249, China; Tel: 010-8973.2239; E-mail: 05250815@163.com considered to be the lower boundary of yield point which is capable to keep solids suspending in case of pump stoppage. In other words, the plastic viscosity and yield point in circulation are required within reasonable limits.

\section{ASSUMPTION}

To facilitate our research, and simplify our mathematical model, the microstructure of particle has not been considered. All particles are assumed spherical. And solid phase is assumed to have uniformly distributed in the physical space they share. Diameters of solid particles and drilling fluid density are assumed to be constant. In addition, allowed pressure of equipment $\&$ pipe lines are considered to be higher than that of drilling fluid pump. When come to calculations, it is assumed that all parameters have certain value except for the particular one which we are talking about.

\section{PERMITTED YIELD POINT CONTROL BOUND- ARY}

\subsection{The Lower Boundary}

For particle in fluid, there are only two states: settlement or natural suspension status [8]. For various reasons, such as pipe connection, log, outage time, etc., drilling fluid circulation had to be stopped temporarily or even for a long time. Therefore, it is usually required that particles in borehole could remain in suspension when drilling fluid circulation stopped. In addition, cuttings settling velocity is required below the drilling fluid velocity in annular to ensure formation cuttings are timely carried out. Meanwhile, good rheological is also very important for efficient rock-breaking. 
In this paper, spherical particles of density of $\rho_{s}(i)$, diameter of $d_{s}(i)$, is considered in an unbounded fluid, the particle will experience a downwards gravitational force, $G_{s}(i)$, and upwards buoyancy force, $F_{b}(i)$, together with the upwards shear force $T_{s}(i)$. Force diagram as shown in Fig. (1).

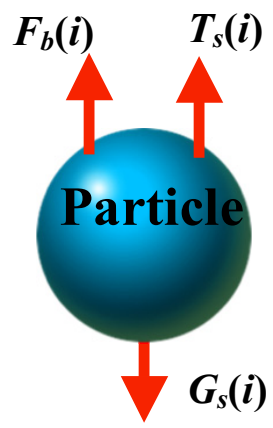

Fig. (1). Force diagram.

When $G_{s}(i), F_{b}(i)$ and $T_{s}(i)$ are in critical force balance, there is,

$G_{s}(i)=F_{b}(i)+T_{s}(i)$

In which

$G_{s}(i)=\left[\pi \rho_{s}(i) g d_{s}^{3}(i)\right] / 6$

$F_{b}(i)=\left[\pi \rho_{m} g d_{s}^{3}(i)\right] / 6$

$T_{s}(i)=\pi^{2} d_{s}^{2}(i) \tau_{s}(i) / 4$

Where suffix " $i$ " mean the same parameter in different individual. $g$ is gravity acceleration, $\mathrm{N} / \mathrm{kg} . \rho_{m}$ is drilling fluid density, $\mathrm{kg} / \mathrm{m}^{3} \cdot d_{s}(i)$ is particle diameter, m. $\rho_{s}(i)$ is particle density, $\mathrm{kg} / \mathrm{m}^{3} . \tau_{s}(i)$ is an effective shear stress which keep the particle in suspension, $\mathrm{Pa}$.

Equation (1) (4) can be organized into:

$\tau_{s}(i)=\frac{2 d_{s}(i)\left[\rho_{s}(i)-\rho_{m}\right] g}{3 \pi}$

For a Bingham fluid,

$\tau=\tau_{0}+\eta_{P V} \gamma$

Where $\tau$ is the local shear stress, $\mathrm{Pa} . \tau_{o}$ is yield point, $\mathrm{Pa}$. $\eta_{P V}$ is the plastic viscosity, $\mathrm{mPa} \cdot \mathrm{s}$. and $\gamma$ is the local shear rate, $\mathrm{s}^{-1}$.

When the shear stress in the fluid becomes larger than $\tau_{o}$ there is a relative flow between the particle and fluid and here is a finite local shear rate $\gamma$ that will generate an additional drag on the particle. The $\max \left\{\tau_{s}(i)\right\}$ in equation (5) provides an estimate for the lowest value of yield point which keep particle in suspension.

\subsection{The Upper Boundary}

Since the rated pressure of pump is certain, and allowed pressure loss in circulation should be smaller than rated pressure of pump, it is possible to evaluate the upper boundary of the drilling fluid yield point with high precision. In other words, it is the rated pump pressure that has limited the maximum value of yield point when other parameters are constant. Hence, relationship between rheological parameters and pressure loss for laminar flow is presented below.

\subsubsection{Pressure Drop in Drill Pipe}

Pressure drop in drill pipe can be calculated by equation (7) [8].

$\Delta P_{s t}(\Delta h)=\frac{8 \eta_{P V}(h) v_{s t}(h)}{R(h)^{2} F(\xi)} \Delta h$

Where $\Delta P_{s t}(\Delta h)$ is pressure drop in drill pipe, $\mathrm{Pa} . \Delta h$ is pipe length, m. $h$ is depth, m. $R(h)$ is inner radius of pipe, m. $v_{s t}(h)$ is velocity of fluid in drill pipe, $\mathrm{m} / \mathrm{s}$.

$F(\xi)=1-\frac{4}{3} \frac{R_{0}(h)}{R(h)}+\frac{1}{3}\left(\frac{R_{0}(h)}{R(h)}\right)^{4}$

Where $R_{0}(h)$ is the distance to borehole axis where its shear stress is equal to $\tau_{0}(h), \mathrm{m}$.

Relationship between yield point $\tau_{0}(h)$ and pressure drop is defined by equation (9):

$\tau_{0}(h)=\frac{\Delta P_{s t}(h)}{2 \Delta h} R_{0}(h)$

\subsubsection{Pressure Drop in Annular Pipe}

Concentric Annulus pressure drop can be calculated by equation (10) [8].

$\Delta P_{a n}(\Delta h)=\frac{\left\{24 \eta_{P V}(h) Q-8 \pi \tau_{0}(h)\left[2 R_{m}^{3}(h)-R_{1}^{3}(h)-R_{2}^{3}(h)\right]\right\} \cdot \Delta h}{3 \pi\left\{R_{2}^{4}(h)-R_{1}^{4}(h)-\frac{\left[R_{2}^{2}(h)-R_{1}^{2}(h)\right]^{2}}{\left.\ln \left[R_{2}(h) / R_{1}(h)\right]\right\}}\right.}$

Where $\Delta P_{a n}(\Delta h)$ is pressure drop in annular through pipe length $\Delta h$, Pa. $Q$ is pump discharge, $\mathrm{m}^{3} / \mathrm{s} . R_{1}(h)$ is drill pipe (or drill collar) outer radius, m. $R_{2}(h)$ is borehole radius, m. $R_{m}(h)$ is the distance from borehole axis to where flow rate shows its maximum value, and $R_{m}(h)$ can be calculated by equation (11).

$R_{m}(h)=\sqrt{\frac{R_{2}^{2}(h)-R_{1}^{2}(h)}{2 \ln \left[R_{2}(h) / R_{1}(h)\right]}}$

\subsubsection{Bit Pressure Drop}

The bit pressure drop can be calculated by experimental equation (12) [9]. 
Table 1. Base data used for calculation.

\begin{tabular}{|l|l|l|l|}
\hline Input Parameters & Value & Input Parameters & Value \\
\hline \hline Well depth $(\mathrm{m})$ & 6684 & Weighting material density $\left(\mathrm{g} / \mathrm{cm}^{3}\right)$ & 4.2 \\
\hline Well diameter $(\mathrm{m})$ & 0.2413 & Ground high pressure line length $(\mathrm{m})$ & 30 \\
\hline Drill pipe ID $(\mathrm{m})$ & 0.1016 & Ground high pressure line ID $(\mathrm{m})$ & 0.1086 \\
\hline Drill pipe OD $(\mathrm{m})$ & 0.127 & Standpipe length $(\mathrm{m})$ & 30 \\
\hline Nozzle equivalent diameter $(\mathrm{m})$ & 0.055902 & Standpipe ID $(\mathrm{m})$ & 0.1086 \\
\hline Nozzle discharge coefficient, dimensionless & 0.9 & Drilling hose length $(\mathrm{m})$ & 30 \\
\hline Cuttings diameter $(\mathrm{cm})$ & 0.5 & Drilling hose ID $(\mathrm{m})$ & 0.1086 \\
\hline Cuttings density $\left(\mathrm{g} / \mathrm{cm}^{3}\right)$ & 2.6 & Kelly bar length $(\mathrm{m})$ & 11.4 \\
\hline Weighting material diameter $(\mathrm{cm})$ & 0.02 & Kelly bar ID $(\mathrm{m})$ & 0.0826 \\
\hline Weighting material density $\left(\mathrm{g} / \mathrm{cm}^{3}\right)$ & 4.2 & & \\
\hline
\end{tabular}

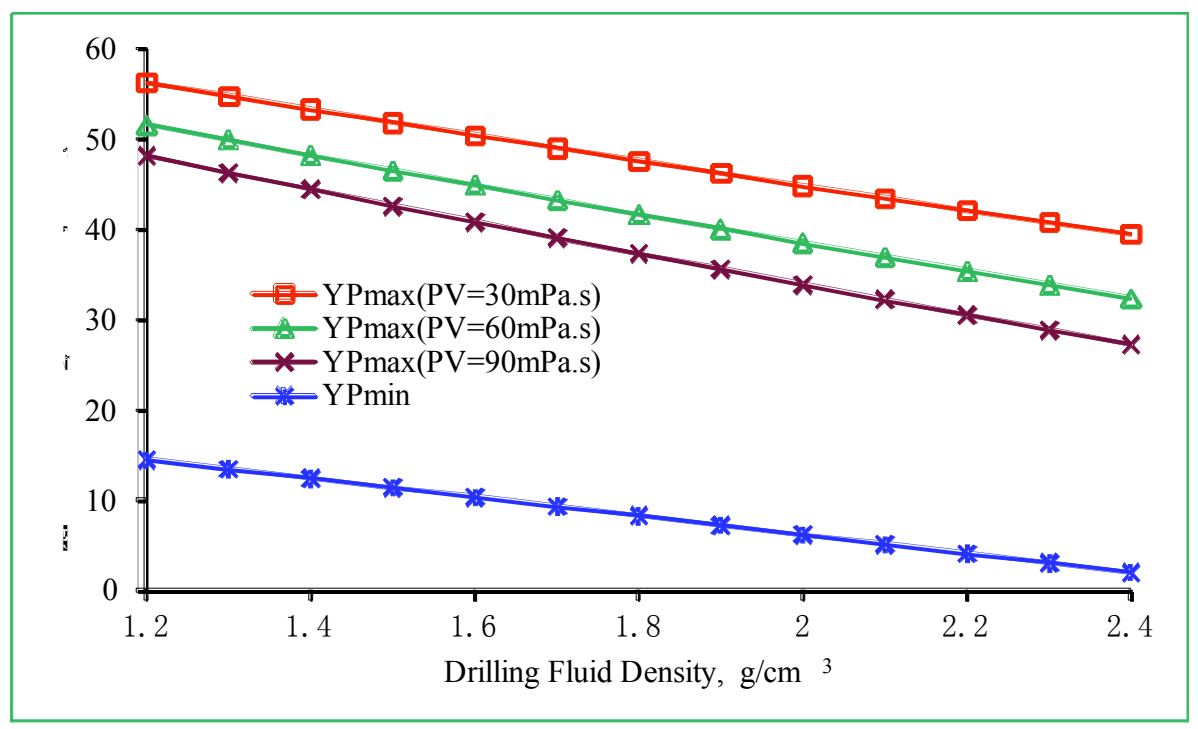

Fig. (2). Permitted yield point control boundary for different drilling fluid density.

$\Delta P_{b}=\frac{0.513559 \rho_{m} Q^{2}}{C^{2} A_{n}^{2}}$

Where $\Delta P_{b}$ is bit pressure drop, Pa. $A_{n}$ is the total area of jet nozzle, $\mathrm{m}^{2} . \quad C$ is flow coefficient of jet nozzle, dimensionless.

Obviously, $\Delta P_{b}$ increase as $\rho_{m}$ and / or $Q$ increase, decrease as $A_{n}$ increase.

\subsubsection{Pressure Drop in Ground Pipelines}

Pressure drop in ground pipelines can be calculated by equation (13) [10].

$\Delta P_{g}(i)=0.1297 \rho_{m}^{0.8} \eta_{P V}^{0.2}(h) \frac{L(i)}{d^{4.8}(i)} Q^{1.8}$

Where $\Delta P_{g}(i)$ is ground pipeline pressure drop, Pa. $L(i)$ is length of each ground pipeline, m. $d(i)$ is inner diameter of each ground pipeline, $\mathrm{m}$.
Obviously, $\Delta P_{g}(i)$ increase as $Q, \rho_{m}$ and / or $\eta_{P V}(h)$ increase.

From above, the total pressure loss $\Delta P$ in circulation can be calculated by equation (13).

$\Delta P=\sum_{h=0}^{H}\left[\Delta P_{s t}(\Delta h)\right]+\sum_{h=0}^{H}\left[\Delta P_{a n}(\Delta h)\right]+\Delta P_{b}+\sum_{i=1}^{n}\left[\Delta P_{g}(i)\right]$

Where $\Delta P$ is the total pressure loss in circulation, MPa. $H$ is well depth, $\mathrm{m}$.

It is clear that high plastic viscosity and yield point may cause excessive circulating pressure loss. Moreover, those cases can reduce bit hydraulic horsepower, and increase the workload of the drilling fluid pump. Even worse, formation may be fractured, or it may cause the needed pump pressure for circulation out of its allowed pump pressure, and then, a series of other emergencies is in the consequent.

To ensure a safe pressure of the pump, it is necessary to adjust drilling fluid plastic viscosity and yield point to meet the critical condition that the total pressure loss in circulation is lower than the rated pressure of equipment, equation is 


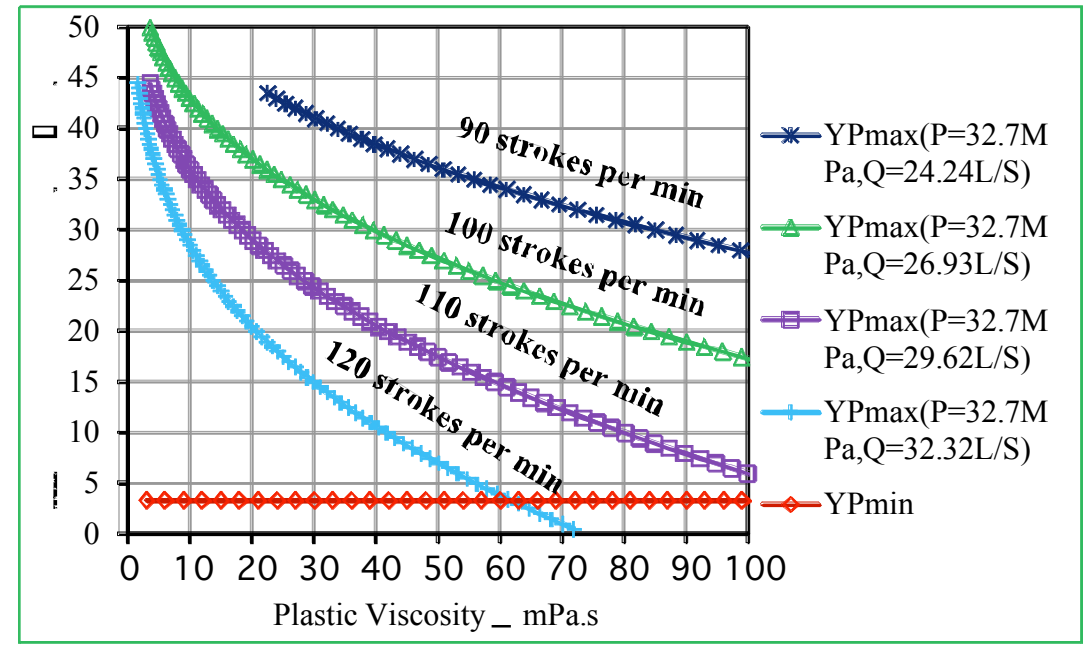

Fig. (3). Permitted yield point control boundary for different plastic viscosity under different pump discharges (or pump strokes) when cylinder bore is $\Phi 150 \mathrm{~mm}$, and other parameters are constants.

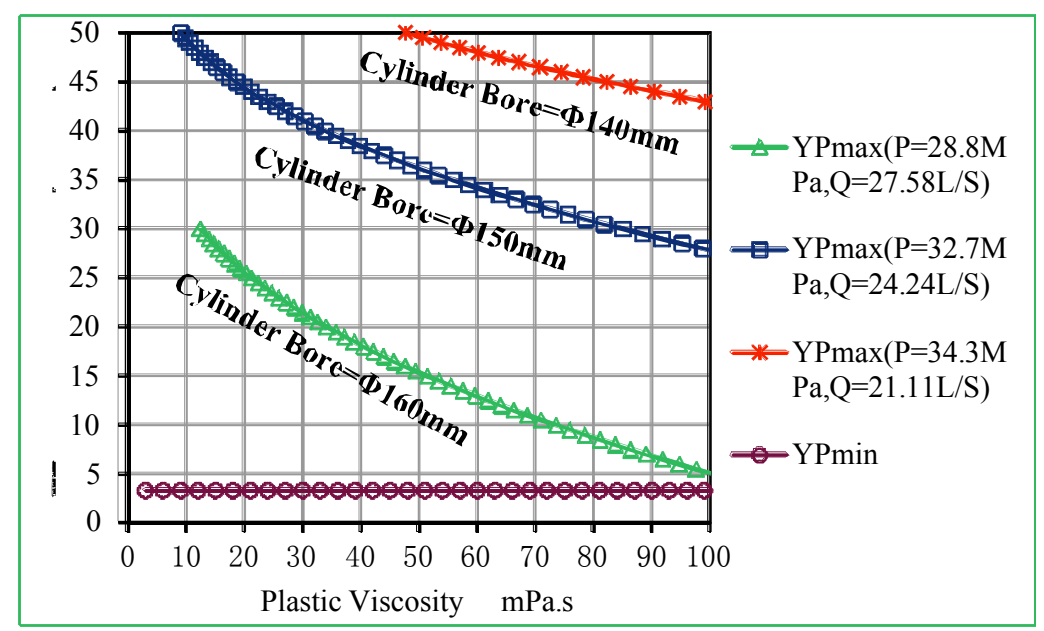

Fig. (4). Permitted yield point control boundary with different plastic viscosity under different cylinder bore when other parameters are constants.

$\Delta P \leq \alpha P_{r p}$

Where $P_{r p}$ is the rated pump pressure, $\mathrm{Pa} . \alpha$ is safe coefficient of rated pump pressure, dimensionless, set by field technician.

Obviously, plastic viscosity and yield point which meet the critical condition of equation (15) are called the upper boundary of themselves.

From above, it is concluded that the value of plastic viscosity and yield point should better lies within the boundary determined by formula (5) and formula (15) which is named "the Permitted Yield Point Control Boundary" by authors.

\section{APPLICATION AND DISCUSSION}

Based on equations referred above, we developed the corresponding calculation software in c\#. Newton iterative method, trial method, etc. are used in programming process to calculate the yield limits. The results are output to the excel format, and then, mapping according to these data use
Excel 2010. Take Tarim oil field KS8 well as example for calculation of permitted yield point control boundary Figs. ( 2 and 4). The base data used for calculation are given in table 1.

As F-1600 drilling fluid pump (made by CNPC) were used on KS8 well, Fig. (2) illustrates the decrease of the upper and lower limits of yield point as drilling fluid density increase when well depth is $6684 \mathrm{~m}$, rated pressure of pump is $32.7 \mathrm{MPa}$, safe coefficient $\alpha$ is 0.8 , pump discharge is $24.24 \mathrm{~L} / \mathrm{s}$, plastic viscosity values were $30,60,90 \mathrm{mPa} \cdot \mathrm{s}$ separately. Under the premise of keeping cuttings in suspension, the value of yield point is recommended a little higher than the lower boundary.

Then, the upper and lower boundary of yield point was calculated under the condition of $\Phi 150 \mathrm{~mm}$ cylinder bore with different pump discharges $(\mathrm{Q})$ and pump pressures $(\mathrm{P})$ when other parameters are constants Fig. (3). From Fig. (3), the upper boundary of yield point decrease as plastic viscosity and / or pump discharge and increase.

The experimental well appeared fluid leakage in a deep of $6684 \mathrm{~m}$ when drilling fluid density is $2.28 \mathrm{~g} / \mathrm{cm}^{3}$. Taking 
the need of drilling field into account, drilling fluid density should not be decreased, while cylinder bore should be increased to $\Phi 160 \mathrm{~mm}$. Fig. (4) illustrate the permitted yield point control boundary with different plastic viscosity under different cylinder bore while pump strokes is 90 per min, and other parameters are constants. From above, according to Fig. (4), plastic viscosity were controlled between $65 \sim 70 \mathrm{mPa} \cdot \mathrm{s}$ and yield point were controlled between $6 \sim 9 \mathrm{~Pa}$ in KS8 well. Pump pressure appeared about 22.5MPa. And finally, we blocked fluid leakage smoothly. Application had shown the practicality and accuracy of this model in Tarim oil field KS8 well.

\section{CONCLUSION}

To consider the needs for drilling and the principles of carry and suspend formation cuttings, the permitted yield point control boundary model of drilling fluid was derived using solid-liquid dynamics under certain given assumptions. Corresponding calculation software was developed in c\#. Newton iterative method, trial method, etc. are used in programming process to calculate the yield point boundary.

This study provides a useful method for field personnel to determine drilling fluid plastic viscosity and yield point regulate target with different well structures, drilling fluid densities, depth, and etc., it will make the regulation a clear task, and provide a useful theoretical reference by a new method for calculation of permitted yield point control boundary of drilling fluid discussed above.

Any one of the drilling fluid density, pump discharge, plastic viscosity and drilling fluid pump cylinder bore increases would result in the permitted yield point control boundary which turned out to be narrow. Drilling fluid pump discharge is the main cause of the decrease in the upper range of the permitted yield point control boundary. While drilling fluid density is the main cause of the decrease in the lower range.

Application in Tarim oil field KS8 well had shown the practicality and accuracy of the permitted yield point control boundary of drilling fluid.

\section{CONFLICT OF INTEREST}

The authors confirm that this article content has no conflict of interest.

\section{ACKNOWLEDGEMENTS}

The study was supported by Innovation Research Group, National Natural Science Fundation of China(Project NO. 51221003) and the National Science and Technology Major Project (Project NO. 2011ZX05021-004).

\section{REFERENCES}

[1] A. Hayatdavoudi, "Drilling with a one-step solids-control technique", SPE Drilling Engineering. vol. 03, pp. 31-40, 1989.

[2] B. Demirdal, and J.C.S Cunha, "Pressure Losses of Non-Newtonian Fluids in Drilling Operations", International Oil Conference and Exhibition in Mexico. Society of Petroleum Engineers, Veracruz, Mexico, 2007.

[3] S.S. Costa, S. Stuckenbruck, S.A.B. Fontoura, and A. Leibsohn, "Simulation of Transient Cuttings Transportation and ECD in Wellbore Drilling”, Europec/EAGE Conference and Exhibition. Society of Petroleum Engineers, Rome, Italy, 2008.

[4] T. Hemphill, K. Ravi, P. A. Bern, and J. C. Rojas, "A Simplified Method for Prediction of ECD Increase with Drillpipe Rotation", SPE Annual Technical Conference and Exhibition. Society of Petroleum Engineers, Denver, Colorado, USA, 2008.

[5] S.T. Johansen, P. Skalle, and J. Sveen, "A generic model for calculation of frictional losses in pipe and annular flows", Journal of Canadian Petroleum Technology, vol. 42, pp. 28-37, 2003.

[6] M.E. Ozbayoglu, and M. Sorgun, "Frictional Pressure Loss Estimation of Non-Newtonian Fluids in Realistic Annulus with Pipe Rotation", Canadian International Petroleum Conference, Petroleum Society of Canada, Calgary, Alberta, 2009.

[7] C.M. Scheid, L.A. Calcada, D.C. Rocha, P.E. Aranha, A.F.L. Aragao, and A. Leibsohn Martins, "Prediction of Pressure Losses in Drilling Fluid Flows in Circular and Annular Pipes and Accessories", Latin American and Caribbean Petroleum Engineering Conference, Society of Petroleum Engineers, Cartagena de Indias, Colombia, 2009.

[8] C. Jialang, L. Yongjian, and Y. Xiang'an, Flux Law of Drilling Fluid. Petroleum Industry Press, Beijing, 1997.

[9] X. Qiang, "Pressure distribution of hydraulic perforation study and hydraulic parameters optimization design on hydrajet-fracturing", China University of Petroleum (Beijing), Beijing, 2009.

[10] C. Tinggen, and G. Zhichuan, Drilling engineering theory and technology. China University of Petroleum Press, Dongying, 2000

This is an open access article licensed under the terms of the Creative Commons Attribution Non-Commercial License (http://creativecommons.org/licenses/by-nc/3.0/) which permits unrestricted, non-commercial use, distribution and reproduction in any medium, provided the work is properly cited. 